\title{
Diabetic Foot Complications among Patients Attending a Specialist Diabetes Clinic in Jamaica: Prevalence and Associated Factors

\author{
TS Ferguson ${ }^{1}$, MK Tulloch-Reid ${ }^{1}$, NOM Younger ${ }^{1}$, RA Wright-Pascoe ${ }^{2}$, MS Boyne ${ }^{1}$, SR McFarlane ${ }^{1}$,
} \\ DK Francis ${ }^{1}$, RJ Wilks ${ }^{1}$
}

\begin{abstract}
Objectives: To estimate the prevalence of diabetic foot complications among patients at a specialist diabetes clinic in Jamaica and identify factors associated with foot complications.

Methods: A stratified random sample of 188 patients were interviewed and examined between 2009 and 2010. Trained nurses obtained demographic and clinical data, measured anthropometrics and performed foot examinations including inspection for amputations, ulcers or infection and assessment of pain, vibration and pressure perception.

Results: Participants included 143 women and 45 men (mean age 56 years; mean diabetes duration 16 years). The prevalence of amputations was 8.5\% (95\% CI 4.5, 12.5\%) and was higher among men $(22.2 \%)$ compared to women $(4.2 \%, \mathrm{p}<0.05)$. Prevalence of current ulcers and current foot infections was $4.3 \%$ and $3.7 \%$, respectively. Overall, $12 \%$ of patients had at least one of these foot complications. Foot complications were more prevalent among men, patients with high blood pressure (BP $\geq 130 / 80$ $\mathrm{mmHg}$ ) or peripheral neuropathy. In multivariable logistic regression models, factors associated with foot complications were: neuropathy (OR 9.3 [95\% CI 2.8, 30.3]), high BP (OR 7.9 [1.3, 49.7]) and diabetes duration (OR 1.32 [1.02, 1.72]).

Conclusion: Approximately one of every eight patients in this specialist clinic had a major foot complication. Associated factors were neuropathy, high blood pressure and longer duration of diabetes.
\end{abstract}

Keywords: Amputations, Caribbean, diabetic foot, diabetic foot infections, diabetic foot ulcers, Jamaica

\section{Complicaciones del Pie Diabético entre Pacientes que Asistían a una Clínica Especializada de Diabetes en Jamaica: Prevalencia y Factores Asociados}

\author{
TS Ferguson ${ }^{1}$, MK Tulloch-Reid ${ }^{1}$, NOM Younger ${ }^{1}$, RA Wright-Pascoe ${ }^{2}$, MS Boyne ${ }^{1}$, SR McFarlane ${ }^{1}$, \\ DK Francis ${ }^{1}$, RJ Wilks ${ }^{1}$
}

\begin{abstract}
RESUMEN
Objetivos: Estimar la prevalencia de complicaciones de pie diabético entre pacientes de una clínica especializada en diabetes en Jamaica, e identificar los factores asociados con complicaciones de pie. Sujetos y métodos: Se realizaron entrevistas y exámenes a una muestra aleatoria estratificada de 188 pacientes entre 2009 y 2010. Enfermeras entrenadas obtuvieron datos demográficos y clínicos, realizaron mediciones antropométricas, así como exámenes de pie - incluyendo la inspección de las amputaciones, las úlceras o infección, y evaluación de la percepción del dolor, la vibración y la presión. Resultados: Los participantes incluyeron 143 mujeres y 45 hombres (edad promedio: 56 años; duración promedio de la diabetes: 16 años). La prevalencia de las amputaciones fue 8.5\% (IC de 95\%: 4.5, $12.5 \%)$ y fue mayor entre los hombres $(22.2 \%)$ en comparación con las mujeres $(4.2 \%, \mathrm{p}<0.05)$. La prevalencia de las úlceras e infecciones de pie corrientes fue de 4.3\% y 3.7\%, respectivamente. En general, $12 \%$ de los pacientes tenían al menos una de estas complicaciones de pie. Las complicaciones de pie fueron más frecuentes entre los hombres, los pacientes con hipertensión arterial (BP $\geq 130 / 80$ $\mathrm{mmHg}$ ), o con neuropatía periférica. De acuerdo con los modelos de regresión logística multivariable,
\end{abstract}

From: ${ }^{1}$ Tropical Medicine Research Institute and ${ }^{2}$ Department of Medicine, The University of the West Indies, Kingston 7, Jamaica, West Indies.
Correspondence: Dr T Ferguson, Tropical Medicine Research Institute (Epidemiology Research Unit), The University of the West Indies, Kingston 7, Jamaica, West Indies. Fax: (876) 927-2984, e-mail: trevor.ferguson02 @uwimona.edu.jm 
los factores asociados con las complicaciones de pie fueron: la neuropatía (OR 9.3 [95\% CI 2.8, 30.3]), BP alto (OR $7.9[1.3,49.7])$ y la duración de la diabetes (OR 1.32 [1.02, 1.72]).

Conclusión: Aproximadamente uno de cada ocho pacientes en esta clínica especializada tuvo una complicación de pie importante. Los factores asociados fueron: neuropatía, presión alta y mayor duración de la diabetes.

Palabras claves: Amputaciones, Caribe, pie diabético, infecciones del pie diabético, úlceras del pie diabético, Jamaica

West Indian Med J 2013; 62 (3): 217

\section{INTRODUCTION}

Foot complications including ulcers, infections and amputations are major causes of morbidity and disability in persons with diabetes mellitus (1). Foot ulceration occurs in approximately $15-25 \%$ of people with diabetes while amputation prevalence ranges from $0.2-4.8 \%(2-4)$. Eightyfive per cent of lower limb amputations in patients with diabetes are preceded by foot ulcers (2). In addition to the morbidity, diabetic foot complications are associated with high mortality $(5,6)$. Cost of care related to foot complications is also significant, with up to $20 \%$ of total expenditure on diabetes in North America and Europe being attributable to the diabetic foot (7). It is widely accepted that foot complications may be prevented by screening patients with diabetes for characteristics which put their feet at high risk of amputation or ulceration, such as impaired sensation and impaired arterial blood flow, and by implementing foot care education and treatment programmes (1).

Diabetic foot complications are common in the English-speaking countries of the Caribbean. In one study from Barbados, Hennis et al documented an incidence of lower extremity amputations of 936/100 000 in the diabetic population. The standardized incidence of lower extremity amputation among the women was second only to that of the Navajo population in the United States of America (8). In Trinidad and Tobago, a cross-sectional study among primary healthcare clinics found that $12 \%$ of persons with diabetes reported previous foot ulceration and $4 \%$ reported previous amputation (9). There are few data on diabetic foot complications in Jamaica; however, a small survey of patients at the diabetes clinic at the University Hospital of the West Indies (UHWI) found that $82 \%$ of participants had clinical signs of peripheral neuropathy and $61 \%$ had ankle-brachial index of $<1.0$ (10). In another study among patients with diabetes admitted to the UHWI in 2005, six per cent had an amputation during that admission (11). There are no published data on the prevalence of diabetic foot complications among patients attending specialist diabetes clinics in the English-speaking Caribbean.

With the prevalence of diabetes mellitus in Jamaica at $8 \%$ (12) and in the context of a global burden of diabetes now estimated at 366 million (13), reliable estimates of the burden of diabetes complications are required to inform the provision of appropriate heath services and to design inter- ventions to address these problems. This study therefore aimed to estimate the prevalence of diabetic foot complications among patients attending the diabetes clinic at UHWI in Jamaica and to identify factors associated with foot complications in this setting.

\section{SUBJECTS AND METHODS}

We conducted a cross-sectional survey of patients attending the UHWI diabetes clinic, a specialist clinic staffed by endocrinologists or diabetes specialists and residents in the UHWI internal medicine training programme. This clinic provides care for a wide cross-section of patients with diabetes including persons from the hospital community and patients referred for specialist care from primary and secondary care facilities.

The study was conducted between August 2009 and September 2010. A list of all 552 patients seen in the UHWI diabetes clinic in 2008 was used as the sampling frame, from which a sex-stratified random sample of 337 persons were selected, aiming to enroll 278 persons (assuming a 20\% nonresponse rate). This sample size was calculated using a $12 \%$ prevalence of foot complications, an acceptable error of $4 \%$, power of $0.8, \alpha=0.05$ and was adjusted using a finite population correction. The study was approved by the University Hospital of the West Indies/University of the West Indies/ Faculty of Medical Sciences Ethics Committee.

\section{Recruitment}

Persons selected for the study were contacted by telephone or on their clinic visit and invited to participate in the study. Written informed consent was obtained prior to data collection and measurements. We successfully ascertained vital status or made contact with 253 (75\%) of the potential participants of which 188 (56\% of targeted sample; $74 \%$ of contacted persons) were enrolled. Fifteen of the targeted persons were reported to have died. Other reasons for non-participation included being unable to get time off from work, difficulty with transportation and being too ill.

\section{Measurements and definitions}

All measurements were performed by trained staff. An interviewer-administered questionnaire was used to collect information on general health, diabetes control and diabetes complications. Socio-economic status was assessed using 
information on education and employment, also obtained by questionnaire. Education level, reported in categories ranging from "no schooling" to "tertiary education", was collapsed into two categories - "secondary or less" and "post-secondary" for analysis. Employment status was categorized as employed, unemployed or other (retired, students or housewives). Data were also collected on cigarette smoking patterns and participants placed into two categories - nonsmokers and past/current smokers.

Body weight was measured to the nearest 0.1 kilogram using a portable digital scale, while height was measured to the nearest 0.1 centimetre using a portable stadiometer. Body mass index (BMI) was calculated as weight in kilograms divided by the square of height in metres and participants categorized as not overweight (BMI $<25 \mathrm{~kg} / \mathrm{m}^{2}$ ), overweight (BMI $\left.25.0-29.9 \mathrm{~kg} / \mathrm{m}^{2}\right)$ or obese (BMI $\geq 30 \mathrm{~kg} / \mathrm{m}^{2}$ ). Waist and hip circumference were obtained using a non-stretchable tape. Waist circumference was measured midway between the lowest rib and the iliac crest, and hip circumference at the level of the greater trochanter.

Blood pressure (BP) was obtained using a mercury sphygmomanometer. Three blood pressure measurements were taken at one minute intervals using the right arm after the participant had been seated for five minutes (14). The mean of the second and third BP measurements was used in the analysis. Participants were classified as having high blood pressure (systolic BP $\geq 130 \mathrm{~mm} \mathrm{Hg}$ or diastolic BP $\geq$ $80 \mathrm{~mm} \mathrm{Hg}$ or being on medication for high blood pressure) or 'not hypertensive' (systolic BP $<130$, diastolic $\mathrm{BP}<80$ and not on antihypertensive medications) in accordance with the American Diabetes Association Standards of Care guidelines (15).

A capillary blood sample was collected for the measurement of haemoglobin A1c (HbAlc) using a point of care instrument $\left(\mathrm{NycoCard}^{\circledR}\right.$ Reader II, AXIS-SHIELD, Rodelokka, Oslo, Norway). Categories of glycaemic control were defined as: good control, $\mathrm{HbAlc}<7.0$; inadequate control, HbAlc 7.0-8.9; poor control, HbA1c $\geq 9.0$.

A comprehensive foot examination was performed in accordance with the guidelines by the Foot Care Interest Group of the American Diabetes Association (4). The foot examination included the following components: inspection for callus, deformities, infection, ulcers and amputation; neurological examination checked vibration perception, pain perception and pressure perception. Vibration perception was assessed at the dorsal aspect of the distal interphalangeal joint of the great toe using a $128 \mathrm{~Hz}$ tuning fork. Pain and pressure sensation was assessed using the Neuropen ${ }^{\circledR}$ device [Owen Mumford, Oxford, England] (16). Pain perception was assessed $0.5 \mathrm{~cm}$ proximal to the nail-fold of the great toe using pin prick delivered by Neurotips ${ }^{\circledR}$ from the Neuropen ${ }^{\circledR}$ device. Pressure perception was assessed using a 10 gram monofilament on the Neuropen ${ }^{\circledR}$ device. The test was performed on the plantar surface of the great toe and the plantar surface of the heads of the $1^{\text {st }}, 3^{\text {rd }}$ and $5^{\text {th }}$ meta-tarsals. For the analysis, three sites on each foot were used: plantar surface on the great toe and over the $3^{\text {rd }}$ and $5^{\text {th }}$ metatarsal head. Failure to appreciate pressure at any of these three sites was considered abnormal (17).

Vascular examination was performed using a portable Doppler ultrasound device (Huntleigh Health Care MultiDopplex II ${ }^{\circledR}$, with a VP8HS 8MHz probe) to measure systolic pressure in the dorsalis pedis, posterior tibial and brachial arteries for the assessment of ankle/brachial index (ABI). The higher pressure of the dorsalis pedis or posterior tibial artery was divided by the higher pressure of the right or left brachial artery (18). A value for $\mathrm{ABI} \leq 0.9$ was considered positive for peripheral vascular disease (PVD). If ABI was $\geq 1.3$, participants were considered to have non-compressible vessels and therefore excluded from the analysis for $\mathrm{ABI}$ (18).

\section{Statistical analysis}

Data analysis was done using Stata 10.1 (StataCorp, College Station, Texas). Means and proportions were obtained for participant characteristics, diabetes and cardiovascular disease risk factors and for markers of socio-economic status (SES). We then obtained prevalence estimates for diabetic foot complications by these characteristics. Differences in proportions for categorical variables were compared using Chi-squared tests or Fisher's exact test as appropriate, while the $t$-test was used for difference in means.

Multivariable logistic regression was performed and adjusted odds ratios for the presence of the major foot complication (amputations, ulcers, foot infection) were obtained. Initial models included variables which were associated with prevalent foot complications in univariate analysis or were believed to be associated based on previous studies including gender, age, BMI, duration of diabetes, high BP, presence of neuropathy, PVD, education and $\mathrm{HbAlc}$ category. The final models were derived by assessing the impact of individual variables using the likelihood ratio test and evaluating the goodness-of-fit of individual models using Hosmer-Lemeshow test. For the variable for duration of diabetes, missing values were imputed based on the participant's age and gender using the impute command in Stata.

\section{RESULTS}

Characteristics of the participants in the study are shown in Table 1. There were 143 women and 45 men; mean age 56 years and mean duration of diabetes 16 years. Except for a higher mean height among men (172.5 cm vs $159.7 \mathrm{~cm}, p<$ $0.001)$ and higher mean BMI in women $\left(30.2 \mathrm{~kg} / \mathrm{m}^{2}\right.$ vs 27.3 $\left.\mathrm{kg} / \mathrm{m}^{2}, p=0.005\right)$ mean values for the characteristics shown were similar in men and women. There were no differences in the mean age, gender distribution or parish or residence for persons enrolled in the study compared to the entire clinic population. For the targeted sample, response rate was higher among women: $59 \%$ compared to men $47 \%$, but there 
Table 1: Characteristics of study participants with comparison of means by gender

\begin{tabular}{|c|c|c|c|}
\hline Characteristic & $\begin{array}{c}\text { Men } \\
\text { Mean } \pm \text { SD } \\
n=45\end{array}$ & $\begin{array}{c}\text { Women } \\
\text { Mean } \pm \text { SD } \\
\mathbf{n}=\mathbf{1 4 3}\end{array}$ & $\begin{array}{c}\text { Total } \\
\text { Mean } \pm \text { SD } \\
\mathbf{n}=\mathbf{1 8 8}\end{array}$ \\
\hline Age (years) & $56.5 \pm 14.8$ & $55.5 \pm 14.7$ & $55.8 \pm 14.7$ \\
\hline Height $(\mathrm{cm})^{* * *}$ & $172.5 \pm 5.8$ & $159.7 \pm 7.2$ & $162.7 \pm 8.8$ \\
\hline Weight (kg) & $81.0 \pm 16.5$ & $77.1 \pm 16.9$ & $78.1 \pm 16.9$ \\
\hline Body mass index ${ }^{* *}\left(\mathrm{~kg} / \mathrm{m}^{2}\right)$ & $27.3 \pm 5.7$ & $30.2 \pm 6.2$ & $29.5 \pm 6.2$ \\
\hline Waist circumference $(\mathrm{cm})$ & $94.1 \pm 16.4$ & $95.6 \pm 13.8$ & $95.3 \pm 14.4$ \\
\hline Systolic blood pressure (mmHg) & $129.2 \pm 20.4$ & $129.3 \pm 22.2$ & $129.3 \pm 21.7$ \\
\hline Diastolic blood pressure $(\mathrm{mmHg})$ & $71.7 \pm 12.7$ & $70.5 \pm 12.9$ & $70.8 \pm 12.8$ \\
\hline Pulse rate (bpm) & $74.0 \pm 13.0$ & $77.7 \pm 13.9$ & $76.8 \pm 13.8$ \\
\hline HbA1c (\%) & $7.3 \pm 1.6$ & $7.8 \pm 2.0$ & $7.7 \pm 2.0$ \\
\hline Duration of diabetes mellitus (years) & $17.4 \pm 13.7$ & $15.6 \pm 10.6$ & $16.1 \pm 11.4$ \\
\hline Age at diagnosis (years) & $38.9 \pm 15.5$ & $38.8 \pm 13.3$ & $38.6 \pm 13.9$ \\
\hline
\end{tabular}

were no differences in the mean age or parish or residence for responders compared to non-responders.

Table 2 shows the proportion of participants in risk categories for diabetes or cardiovascular disease (CVD), diabetes control and socio-economic status. Seventy-three per cent of participants had high blood pressure, 35\% were overweight and $42 \%$ were obese. Prevalence of past or current cigarette smoking was $27 \%$ with a much higher prevalence among men compared to women $(64 \%$ vs $15 \%, p<0.001)$. Fourteen per cent of participants reported daily smoking. Only two participants reported current smoking; duration since smoking cessation was not available. Seventy per cent of participants reported current insulin therapy. Overall glycaemic control levels were sub-optimal with $42 \%$ classified as having good control and $22 \%$ having poor control.

Table 2: Percentage of participants in cardiovascular disease, diabetes or socio-economic status risk categories

\begin{tabular}{|c|c|c|c|}
\hline Characteristic & $\begin{array}{c}\text { Men } \\
\text { Percentage (SE) } \\
\quad n=45\end{array}$ & $\begin{array}{c}\text { Women } \\
\text { Percentage (SE) } \\
\mathbf{n}=\mathbf{1 4 3}\end{array}$ & $\begin{array}{c}\text { Total } \\
\text { Percentage (SE) } \\
\quad \mathbf{n}=\mathbf{1 8 8}\end{array}$ \\
\hline \multicolumn{4}{|l|}{ Age category } \\
\hline Less than 50 years & $28.9(6.8)$ & $32.2(3.9)$ & $31.4(3.4)$ \\
\hline Fifty years and older & $71.1(6.8)$ & $67.8(3.9)$ & $68.6(3.4)$ \\
\hline \multicolumn{4}{|l|}{ Education level } \\
\hline Secondary or less* & $86.7(5.1)$ & $72.7(3.7)$ & $76.1(3.1)$ \\
\hline Post-secondary* & $13.3(5.1)$ & $27.3(3.7)$ & $23.9(3.1)$ \\
\hline \multicolumn{4}{|l|}{ Employment status } \\
\hline Employed & $46.7(7.5)$ & $37.1(4.1)$ & $39.4(3.6)$ \\
\hline Unemployed & $33.3(7.1)$ & $23.8(3.5)$ & $26.0(3.2)$ \\
\hline Other (retired/housewife/student) & $20.0(6.0)$ & $39.1(4.1)$ & $34.6(3.5)$ \\
\hline \multicolumn{4}{|l|}{ High blood pressure } \\
\hline \multicolumn{4}{|l|}{ 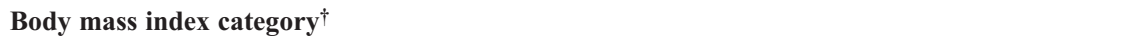 } \\
\hline Overweight (BMI 25-29.9) & $37.2(7.5)$ & $33.8(4.0)$ & $34.6(3.5)$ \\
\hline Obese $(\mathrm{BMI} \geq 30)^{*}$ & $27.9(6.9)$ & $46.0(4.2)$ & $41.7(3.7)$ \\
\hline Past or current smoking ${ }^{* * *}$ & $64.4(0.07)$ & $14.7(0.03)$ & $26.6(0.04)$ \\
\hline Current insulin treatment & $68.9(7.0)$ & $70.6(3.8)$ & $70.2(3.3)$ \\
\hline \multicolumn{4}{|l|}{ Diabetes control } \\
\hline Good (HbAlc < $7.0 \%)$ & $44.4(7.5)$ & $42.0(4.1)$ & $42.3(3.6)$ \\
\hline Inadequate (HbA1c 7-9\%) & $44.4(7.5)$ & $33.2(3.9)$ & $35.1(3.5)$ \\
\hline Poor $(\mathrm{HbA} 1 \mathrm{c} \geq 9 \%)^{*}$ & $11.1(4.7)$ & $25.9(3.7)$ & $22.3(3.0)$ \\
\hline
\end{tabular}

${ }^{*} p<0.05 ;{ }^{* * *} p<0.001 ; p$-values are male:female comparison of proportions for individual risk categories. ${ }^{\dagger}$ Estimates based on 182 participants: 43 males, 139 females; SE $=$ standard error 
Table 3: Prevalence of diabetic foot complications among study participants

\begin{tabular}{|c|c|c|c|}
\hline Characteristic & $\begin{array}{c}\text { Men } \\
\text { Percentage } \\
(95 \% \text { CI) } \\
\mathbf{n}=45\end{array}$ & $\begin{array}{c}\text { Women } \\
\text { Percentage } \\
(\mathbf{9 5 \%} \text { CI) } \\
\mathbf{n}=\mathbf{1 4 3}\end{array}$ & $\begin{array}{c}\text { Total } \\
\text { Percentage } \\
(\mathbf{9 5 \%} \text { CI) } \\
\mathbf{n}=\mathbf{1 8 8}\end{array}$ \\
\hline \multicolumn{4}{|l|}{ Major foot complications } \\
\hline Amputation** & $\begin{array}{c}\mathbf{2 2 . 2} \\
(9.9,34.6)\end{array}$ & $\begin{array}{c}\mathbf{4 . 2} \\
(0.9,7.5)\end{array}$ & $\begin{array}{c}\mathbf{8 . 5} \\
(4.5,12.5)\end{array}$ \\
\hline Ulcer & $\begin{array}{c}\mathbf{6 . 7} \\
(0,14.1)\end{array}$ & $\begin{array}{c}\mathbf{3 . 4} \\
(0.5,6.5)\end{array}$ & $\begin{array}{c}\mathbf{4 . 3} \\
(1.3,7.2)\end{array}$ \\
\hline Foot infection & $\begin{array}{c}4.4 \\
(0,10.6)\end{array}$ & $\begin{array}{c}\mathbf{3 . 5} \\
(0.5,6.5)\end{array}$ & $\begin{array}{c}3.7 \\
(1.0,6.5)\end{array}$ \\
\hline Amputation/Ulcer/Infection ${ }^{* *}$ & $\begin{array}{c}\mathbf{2 6 . 7} \\
(13.5,39.8)\end{array}$ & $\begin{array}{c}7.7 \\
(3.3,12.1)\end{array}$ & $\begin{array}{c}\mathbf{1 2 . 2} \\
(7.5,17.0)\end{array}$ \\
\hline Foot deformity & $\begin{array}{c}\mathbf{8 . 9} \\
(0.4,17.4)\end{array}$ & $\begin{array}{c}9.8 \\
(4.9,14.7)\end{array}$ & $\begin{array}{c}\mathbf{9 . 6} \\
(5.3,13.8)\end{array}$ \\
\hline Peripheral vascular disease (PVD)* & 18.4 & 19.1 & 18.9 \\
\hline (Ankle brachial index $<0.9$ ) & $(5.8,31.0)$ & $(11.7,26.5)$ & $(12.5,25.3)$ \\
\hline \multicolumn{4}{|l|}{ Peripheral neuropathy } \\
\hline Absent pain perception & 22.2 & 11.9 & 14.4 \\
\hline & $(9.9,34.6)$ & $(6.5,17.2)$ & $(9.3,19.4)$ \\
\hline Absent vibration perception & $\begin{array}{c}\mathbf{1 5 . 6} \\
(4.8,26.3)\end{array}$ & $\begin{array}{c}\mathbf{1 1 . 9} \\
(6.5,17.2)\end{array}$ & $\begin{array}{c}\mathbf{1 2 . 8} \\
(8.0,17.6)\end{array}$ \\
\hline $\begin{array}{r}\text { Impaired pressure perception } \\
(10 \mathrm{~g} \text { monofilament })\end{array}$ & $\begin{array}{c}\mathbf{4 2 . 2} \\
(27.5,56.9)\end{array}$ & $\begin{array}{c}\mathbf{3 0 . 8} \\
(23.1,38.4)\end{array}$ & $\begin{array}{c}\mathbf{3 3 . 5} \\
(26.7,40.3)\end{array}$ \\
\hline $\begin{array}{r}\text { Any neuropathy } \\
\text { (impaired } \\
\text { pain/vibration/monofilament) }\end{array}$ & $\begin{array}{c}\mathbf{4 2 . 2} \\
(27.5,56.9)\end{array}$ & $\begin{array}{c}32.2 \\
(24.4,39.9)\end{array}$ & $\begin{array}{c}\mathbf{3 4 . 6} \\
(27.7,41.4)\end{array}$ \\
\hline
\end{tabular}

$* p<0.05 ; * * p<0.01$; estimates are based on foot examination. For PVD, estimates are based on data from 148 participants ( 29 participants had missing data and 11 had ankle brachial index $\geq 1.3$ )

Prevalence estimates for foot complications are shown in Table 3. Overall amputation prevalence was $8.5 \%(95 \%$ confidence interval [CI] 4.5, 12.5\%); men had a significantly higher prevalence of amputations: $22 \%$ compared to $4 \%$ among women $(p<0.01)$. There was full agreement between the prevalence of amputation estimated by self-reports (data not shown) and from foot examination. Of the 16 participants who reported amputations, only one was definitely not due to diabetes, while 13 were reported as being due to diabetes. Two participants did not report the reason for amputation but based on the site of these amputations and the duration of diabetes for these participants, it was thought that these were likely diabetes related amputations. The Figure shows the distribution of amputations by side and site. The majority of amputations were digital amputations but there were eight major amputations (three above knee, three below knee and two trans-metatarsal). Prevalence of current ulcers was $4.3 \%(6.7 \%$ men, $3.4 \%$ women; $p=0.436)$ and prevalence of current foot infection was $3.7 \%$ (4.4\% men and $3.5 \%$ women; $p=0.784)$. In addition to those with current ulcers or infection, $12 \%$ reported a history of past ulcer, resulting in a combined total of past or current ulcers of $16 \%$. Thirteen per cent had a history of past foot infection. We derived a composite outcome for major foot complication representing participants with any one of the following: amputation, current ulcer or current infection. The overall prevalence for this combined foot complication index was $12 \%$ (27\% among men and $8 \%$ among women; $p=0.008)$.

Prevalence of PVD by measured ankle brachial index (ABI) was $19 \%$ with no gender difference. From the sensory examination, $35 \%$ of participants had peripheral neuropathy; impaired pressure perception (by monofilament testing) was the most common feature of neuropathy and was present in $34 \%$ of the entire sample; $14 \%$ of participants had impaired pain perception and $13 \%$ had impaired vibration perception. The monofilament test identified 63 of 65 (97\%) participants classified as having peripheral neuropathy using any of the three tests (ie monofilament, pain perception or vibration perception). In addition to documented neuropathy on examination, there was a high prevalence of neuropathy symptoms. Overall, $71 \%$ of participants reported at least one of the following neuropathy symptoms: burning pain, tingling sensation, numbness and loss of feeling in the foot.

We also evaluated the prevalence of foot examination by categories of CVD or diabetes risk factors and SES categories (data not shown). Statistically significant associations with foot complications were found with peripheral neuropathy and for high blood pressure. There was no significant association between foot complications and current diabetes control (measured by HbA1c) or PVD. 


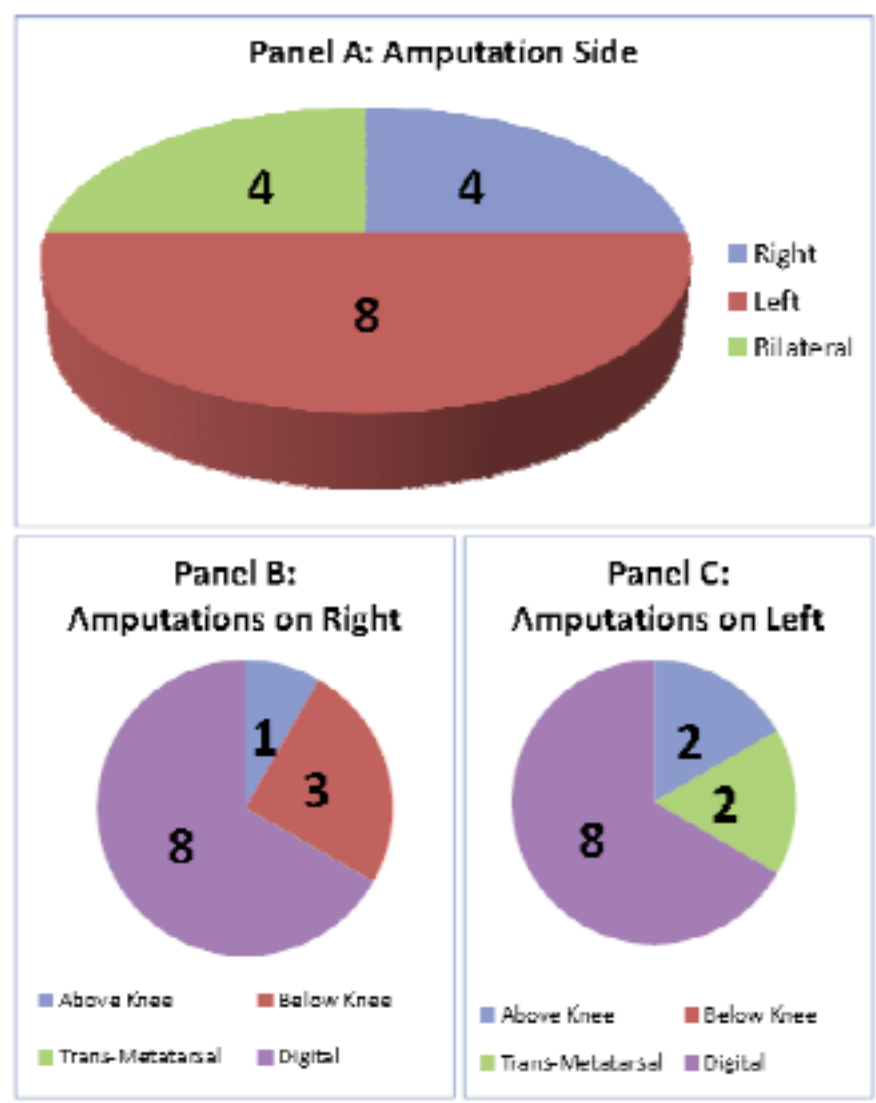

Figure: Number of amputations among study participants by site: rightsided, left-sided or bilateral; above-knee, below-knee, transmetatarsal or digital.

The results from the multivariable logistic regression analyses are shown in Table 4. Analyses for the multivariable models were based on 186 participants due to exclusion of one participant who reported amputation not due to diabetes and one participant with missing data on neuropathy. Duration of diabetes included 29 imputed values based on participant's age and gender. Duration of diabetes, high blood pressure and peripheral neuropathy had strong positive asso- ciation with diabetic foot complications. Odds ratios (OR) for high blood pressure and peripheral neuropathy were 7.9 $(95 \%$ CI $1.3,49.7, p=0.027)$ and $9.3(95 \%$ CI $2.8,30.3, p<$ 0.001 ), respectively. Duration of diabetes (used as a continuous variable) was associated with a $30 \%$ increase in the odds of foot complication per five-year period of diabetes. Older persons were less likely to have foot complications with an adjusted OR 0.69 (95\% CI $0.54,0.90, p=0.005$ ) for each five-year increment in age. After adjustment for cigarette smoking, the odds ratio for foot complications for men compared to women was reduced and no longer statistically significant.

\section{DISCUSSION}

In this study, we report a high prevalence of diabetic foot complications among patients attending a specialist diabetes clinic in Jamaica. The overall prevalence of major foot complications (amputation, current ulcer or current infection) was $12 \%$. Prevalence of amputations was $8.5 \%$ and was higher in men than women, while prevalence of current foot ulcers was $4 \%$ and current foot infection $4 \%$. Thirty-four per cent of participants had neuropathy by sensory testing. Prevalent foot complications were significantly associated with peripheral neuropathy, high blood pressure, duration of diabetes and younger age. Gender differences in the prevalence of foot complications were partially explained by smoking status in multivariable models.

The findings of this study are consistent with other studies which show a high burden of diabetic foot complications in the English-speaking Caribbean territories $(8,9)$. The $8.5 \%$ prevalence of amputations in this study was twice that seen in Trinidad and Tobago (9) and much higher than the range of $0.2-4.8 \%$ seen across all publications reported in the $3^{\text {rd }}$ edition of the International Diabetes Federation Diabetes Atlas (3). Prevalence of previous or current foot ulcers were also higher than that reported from Trinidad and Tobago (16\% in this study compared to $12 \%$ in Trinidad and Tobago). It should be noted, however, that the study in

Table 4: Factors associated with major diabetic foot complications ${ }^{\dagger}$ in multivariable logistic regression models

\begin{tabular}{|c|c|c|c|}
\hline Variable & Odds Ratio & $\begin{array}{l}\text { 95\% Confidence } \\
\text { Interval }\end{array}$ & $p$-value \\
\hline Men ( $v s$ women) & 2.80 & $0.81,9.69$ & 0.105 \\
\hline Age (5-year increments) & 0.69 & $0.54,0.90$ & 0.005 \\
\hline Duration of diabetes (5-year increments) & 1.31 & $1.01,1.70$ & 0.044 \\
\hline High blood pressure & & & \\
\hline$(\geq 130 / 80 \mathrm{mmHg} v s<130 / 80 \mathrm{mmHg})$ & 7.94 & $1.27,49.65$ & 0.027 \\
\hline $\begin{array}{l}\text { Neuropathy present } \\
\text { (vs no neuropathy) }\end{array}$ & 9.27 & $2.84,30.30$ & $<0.001$ \\
\hline $\begin{array}{l}\text { Past or current smoker } \\
\text { (vs non-smoker) }\end{array}$ & 2.24 & $0.60,8.42$ & 0.233 \\
\hline
\end{tabular}

${ }^{\dagger}$ Major foot complication $=$ amputation, current ulcer or current foot infection on foot examination 
Trinidad and Tobago used data from primary care health centres whereas this study used data from a 'tertiary care' specialist diabetes clinic. The participants in Trinidad and Tobago were slightly older than in our sample but had a shorter duration of diabetes (median eight years among those without ulcers and 13 years among those with ulcers, compared to mean duration of 16 years in this study). It is therefore possible that the higher prevalence may be related to a higher proportion of patients with complicated and difficult to control diabetes in the sample. This may be countered, however, by the greater availability of specialist treatment which should lower complication rates. Further studies using population based samples and studies in primary and secondary care settings are needed.

The prevalence of peripheral neuropathy symptoms in this study was $71 \%$ while prevalence of neuropathy by sensory testing was 34\%. Prevalence estimates for diabetic peripheral neuropathy vary widely but our findings seem generally consistent with the literature with prevalence estimates in the region of $30 \%$ on sensory testing and up to $75 \%$ by self-reports (19-23). The prevalence of PVD in this study was somewhat lower than $20-40 \%$ reported in other studies $(23,24)$ and was not associated with prevalent foot complications.

Factors associated with foot complications in the multivariable analyses for this study included peripheral neuropathy, high blood pressure, duration of diabetes and younger age. The association between male gender and cigarette smoking was not statistically significant. Peripheral neuropathy and duration of diabetes were also significant correlates of foot complications in studies from Barbados and Trinidad and Tobago $(8,9)$ and is generally consistent with the literature $(23,25)$. The association with younger age and poor blood pressure control was unexpected and warrants further evaluation. Possible explanations for the association with younger age may include age-related differences in foot care practices and greater exposure to injuries in younger patients. Inadequate blood pressure control may be a marker for vascular disease, thus increasing the risk of ulcer or amputation following foot injury.

Based on the associations found in this study, foot care education for persons with neuropathy and blood pressure control appear to be potential targets for the reduction of foot complications. In light of the high prevalence of peripheral neuropathy, physicians should routinely screen patients with diabetes for evidence of neuropathy and ensure that patients at high risk receive footwear and foot care education $(1,26$, 27). Patients with established foot lesions will need to be referred for specialist care with a podiatrist or in foot care clinics $(26,27)$. It is also important that all patients receive treatment designed to optimize diabetes control as this will prevent or delay neuropathy (28). Qualitative inquiry into factors associated with footwear and foot care practices should also be explored.
This study had some limitations. Firstly, the study site was a tertiary care centre and as such the findings may not be generalizable to all patients with diabetes in Jamaica. Secondly, the small sample size resulted in decreased power to detect sub-group differences in foot complications and relatively wide confidence intervals for prevalence estimates. Although the lower than expected response rate might have decreased the representativeness of the sample, we were able to show that the gender, age and parish of residence distribution of the sample was not different from that of the total clinic population, hence we are confident that these findings are representative of the clinic. The cross-sectional design also limits our ability to make causal inferences from the associations found. The study, however, was strengthened by the use of a random sample from the clinic participants and the use a comprehensive clinical foot examination to assess complications. The use of standardized protocols also served to minimize misclassification. The findings of this study therefore represent the best available estimates of the prevalence of diabetic foot complications in Jamaica.

This study is the first to report prevalence estimates of diabetes foot complications in Jamaica and the first to report on foot complications from a specialist diabetes clinic in the English-speaking Caribbean and will therefore add to the literature on diabetic foot complications in the region. This is particularly relevant in light of the paucity of similar data from developing countries (29). The study will also stimulate further research in this field and provide baseline data to guide interventions aimed at reducing the burden of diabetic foot complications in Jamaica, the Caribbean and other developing countries.

\section{CONCLUSION}

One in eight persons at the UHWI diabetes clinic has a major diabetic foot complication. The $8.5 \%$ prevalence for amputation in this study is higher than in other published studies. Prevalent foot complications were associated with peripheral neuropathy, high blood pressure, duration of diabetes and younger age. Further studies are required to provide a more precise estimate of the prevalence of foot complications at the population level and to aid in the understanding of its behavioural and biological risk factors. Interventions to reduce foot complications need to be developed and evaluated in the Caribbean.

\section{ACKNOWLEDGEMENTS}

The authors wish to thank the study participants, project staff, including nurses (C Bennett, B Walker and $\mathrm{R}$ Walters), administrative staff (N Campbell), and driver (J Campbell) for their contribution to the project. This study was supported by a grant from the Caribbean Health Research Council. Additional support for equipment was obtained through a special donation from a UWI medical alumnus, Dr Earl O’Brien. 


\section{REFERENCES}

1. Mayfield JA, Reiber GE, Sanders LJ, Janisse D, Pogach LM. Preventive foot care in diabetes. Diabetes Care 2004; 27 (Suppl 1): S63-S64.

2. Boulton AJ, Kirsner RS, Vileikyte L. Clinical practice. Neuropathic diabetic foot ulcers. N Engl J Med 2004; 351: 48-55.

3. International Diabetes Federation. Diabetes Atlas. $3^{\text {rd }}$ ed. Brussels: International Diabetes Federation; 2006.

4. Boulton AJM, Armstrong DG, Albert SF, Frykberg RG, Hellman R, Kirkman MS et al. Comprehensive foot examination and risk assessment: a report of the Task Force of the Foot Care Interest Group of the American Diabetes Association, with endorsement by the American Association of Clinical Endocrinologists. Diabetes Care 2008; 31: 1679-85.

5. Boyko EJ, Ahroni JH, Smith DG, Davignon D. Increased mortality associated with diabetic foot ulcer. Diabet Med 1996; 11: 967-72.

6. Hambleton IR, Jonnalagadda R, Davis CR, Fraser HS, Chaturvedi N, Hennis AJ. All-cause mortality after diabetes-related amputation in Barbados: a prospective case-control study. Diabetes Care 2009; 2: 306-7.

7. Boulton AJ, Vileikyte L, Ragnarson-Tennvall G, Apelqvist J. The global burden of diabetic foot disease. Lancet 2005; 366: 1719-24.

8. Hennis AJ, Fraser HS, Jonnalagadda R, Fuller J, Chaturvedi N. Explanations for the high risk of diabetes-related amputation in a Caribbean population of black African descent and potential for prevention. Diabetes Care 2004; 11: 2636-41.

9. Gulliford MC, Mahabir D. Diabetic foot disease and foot care in a Caribbean community. Diabetes Res Clin Pract 2002: 56: 35-40

10. Richards-George P, Wright-Pascoe R, Choo-Kang E, Reid HL, Mills J, Morrison EY. Some clinical factors contributing to the development of the diabetic foot. West Indian Med J 1999; 48: 223-6.

11. Ferguson TS, Tulloch-Reid MK, Younger NO, Boyne MS, WrightPascoe RA, Elliott VE et al. Cardiovascular disease among diabetic inpatients at a tertiary hospital in Jamaica. Diabetes Vasc Dis Res 2010; 7: 241-2.

12. Ferguson TS, Francis DK, Tulloch-Reid MK, Younger NO, Mullings J, Wilks RJ. An update on the burden of cardiovascular disease risk factors in Jamaica: findings from the Jamaica Health and Lifestyle Survey 2007-2008. West Indian Med J 2011; 60: 422-8.

13. Whiting DR, Guariguata L, Weil C, Shaw J. IDF Diabetes Atlas: global estimates of the prevalence of diabetes for 2011 and 2030. Diabetes Res Clin Pract 2011; 94: 311-21.

14. Ataman SL, Cooper R, Rotimi C, McGee D, Osotimehin B, Kadiri S et al. Standardization of blood pressure measurement in an international comparative study. J Clin Epidemiol 1996; 49: 869-77.

15. American Diabetes Association. Standards of medical care in diabetes - 2010. Diabetes Care 2010; 33 (Suppl 1): S11-S61.

16. Paisley AN, Abbott CA, van Schie CH, Boulton AJ. A comparison of the Neuropen against standard quantitative sensory-threshold measures for assessing peripheral nerve function. Diabet Med 2002; 19: 400-5.
17. Feng Y, Schlosser FJ, Sumpio BE. The Semmes Weinstein monofilament examination as a screening tool for diabetic peripheral neuropathy. J Vasc Surg 2009; 50: 675-82.

18. Hirsch AT, Haskal ZJ, Hertzer NR, Bakal CW, Creager MA, Halperin JL et al. ACC/AHA 2005 practice guidelines for the management of patients with peripheral arterial disease (lower extremity, renal, mesenteric, and abdominal aortic): a collaborative report from the American Association for Vascular Surgery/Society for Vascular Surgery, ${ }^{*}$ Society for Cardiovascular Angiography and Interventions, Society for Vascular Medicine and Biology, Society of Interventional Radiology, and the ACC/AHA Task Force on Practice Guidelines (Writing Committee to Develop Guidelines for the Management of Patients With Peripheral Arterial Disease): endorsed by the American Association of Cardiovascular and Pulmonary Rehabilitation; National Heart, Lung, and Blood Institute; Society for Vascular Nursing; TransAtlantic Inter-Society Consensus; and Vascular Disease Foundation. Circulation 2006; 113: e463-e654.

19. Davies M, Brophy S, Williams R, Taylor A. The prevalence, severity, and impact of painful diabetic peripheral neuropathy in type 2 diabetes. Diabetes Care 2006; 29: 1518-22.

20. Halawa MR, Karawagh A, Zeidan A, Mahmoud AE, Sakr M, Hegazy A. Prevalence of painful diabetic peripheral neuropathy among patients suffering from diabetes mellitus in Saudi Arabia. Curr Med Res Opin 2010; 26: 337-43.

21. Janghorbani M, Rezvanian H, Kachooei A, Ghorbani A, Chitsaz A, Izadi $\mathrm{F}$ et al. Peripheral neuropathy in type 2 diabetes mellitus in Isfahan, Iran: prevalence and risk factors. Acta Neurol Scand 2006; 114: 384-91.

22. Young MJ, Boulton AJM, Macleod AF, Williams DRR, Sonksen PH. A multicentre study of the prevalence of diabetic peripheral neuropathy in the United Kingdom hospital clinic population. Diabetologia 1993; 36: $150-4$.

23. Cheer K, Shearman C, Jude EB. Managing complications of the diabetic foot. BMJ 2009; 339: b4905.

24. American Diabetes Association. Peripheral arterial disease in people with diabetes. Diabetes Care 2003; 26: 3333-41.

25. Khanolkar MP, Bain SC, Stephens JW. The diabetic foot. QJM 2008; 101: 685-95.

26. Hunt D. Using evidence in practice. Foot care in diabetes. Endocrinol Metab Clin North Am 2002; 31: 603-11.

27. Singh N, Armstrong DG, Lipsky BA. Preventing foot ulcers in patients with diabetes. JAMA 2005; 293: 217-28.

28. Stratton IM, Adler AI, Neil HA, Matthews DR, Manley SE, Cull CA et al. Association of glycaemia with macrovascular and microvascular complications of type 2 diabetes (UKPDS 35): prospective observational study. BMJ 2000; 321: 405-12.

29. Unwin N. The diabetic foot in the developing world. Diabetes Metab Res Rev 2008; 24 (Suppl 1): S31-S33. 